\title{
A PROSPECTIVE CLINICAL STUDY TO EVALUATE RISK FACTORS FOR AGE RELATED MACULAR DEGENERATION IN CENTRAL INDIA
}

\author{
Kavita Kumar'1, Pooja Bargujar², V. Som³ ${ }^{3}$ S. Kubrey ${ }^{4}$
}

\section{HOW TO CITE THIS ARTICLE:}

Kavita Kumar, Pooja Bargujar, V Som, S Kubrey. "A prospective clinical study to evaluate risk factors for age related macul ar degen eration in central India". Journal of Evolution of Medical and Dental Sciences 2013;

Vol. 2, Issue 44, November 04; Page: 8563-8568.

ABSTRACT: Age related macular degeneration (AMD) is a leading cause of irreversible blindness among the elderly worldwide affecting 30-50 million individuals. AMD is more common in developed world. AMD is characterized by central visual loss. Advanced AMD can be classified in broadly into two types: dry and wet form. Several clear risk factors for the development and progression of age related macular degeneration have been established are advancing age, genetic factors, history of smoking, white race, obesity, high dietary intake of vegetable fat, low dietary intake of antioxidants and zinc. This prospective non-interventional study was conducted from February 2011 to October 2012 in the Regional Institute of Ophthalmology, Hamidia Hospital, Bhopal, included patients who attended the eye OPD, retina clinic and eye ward and were diagnosed as a case of AMD. Present study included 174 patients out of which patients $79(45.39 \%)$ were above the age of 70 years, with 51 (29.31\%) patients between 61-70 years and 44 cases $(25.28 \%)$ in the sixth decade. Male: female ratio was 0.75: 1.21 (12.06\%) patients have a positive family history of AMD. Most common risk factor identified in our study was chronic sun exposure (49.42\%) followed by hypertension in $41.8 \%$ patients. $25.26 \%$ cases gave history of smoking and raised serum cholesterol levels were seen in $14.28 \%$ cases. History of alcoholism was positive in $19.54 \%$ patients. Of the 174 cases in our present study 90 patients (51.72\%) were hypermetropic. Conclusion: Age related macular degeneration is a disease of elderly with risk factors, most of them are preventable. If timely proper measures are taken, a major cause of blindness can be prevented in elderly age group.

INTRODUCTION: Age related macular degeneration (AMD) is a leading cause of irreversible blindness among the elderly worldwide affecting 30-50 million individuals. The World Health Organization (WHO) estimated in 2002 that $8.7 \%$ of the world's blindness was due to AMD with 14 million persons worldwide blind or severely visually impaired. AMD is more common in developed world.

The prevalence of advanced AMD increases with each decade after age of 50 with the highest prevalence occurring after age of 80 . The population over age 85 years is expected to increase by $107 \%$ by the year 2020 , so the prevalence of this disease will continue to rise dramatically. ARMD is characterized by central visual loss as a result of drusen deposition leading to geographical atrophy or choroidal neovascular membrane and its complications.

Several risk factors have been identified for the development and progression of age related macular degeneration like advancing age, genetic factors, a history of smoking within the past 20 years, white race, hypertension, obesity, high dietary intake of vegetable fat, low dietary intake of antioxidants and zinc and certain ocular risk factors like light iris colour, hypermetropia. Most of these risk factors are modifiable and controlling these risk factors reduce chances of development and progression of the disease. 
MATERIAL AND METHOD: This prospective clinical case study was conducted from February 2011 to October 2012 in the Regional Institute of Ophthalmology, Hamidia Hospital, Bhopal and included patients who attended the eye OPD, retina clinic and eye ward and were diagnosed as a case of AMD.

\section{Exclusion Criteria:}

1. Patient $<50$ yrs of age.

2. Patients with disease preventing adequate fundus examination such as cataract, corneal opacity, etc.

3. Patients having other ocular disease or macular pathology that could independently affect visual acuity.

Detailed history of patients was taken to include age, sex, smoking, hypertension, alcohol intake, diet, sun exposure and family history for similar complaints. Ocular complaints were recorded with emphasis on defective distant and near vision, its onset, course, and complaints of distortion of vision, loss of central vision, floaters, and scotoma.

Detailed ocular examination performed including visual acuity both distant and near, slit lamp examination, intra-ocular pressure, color vision, Amsler grid, photo stress test, fundus examination and photography and fluorescein angiography and findings recorded.

OBSERVATION AND RESULTS: We conducted a study of 174 cases of AMD at the Regional Institute of Ophthalmology and assessed them clinically with special reference to age at presentation, type of AMD and associated risk factors.

\begin{tabular}{|c|c|c|}
\hline Age in years & No. of patients & Percentage (\%) \\
\hline $51-60$ & 44 & 25.28 \\
\hline $61-70$ & 51 & 29.3 \\
\hline$>70$ & 79 & 45.39 \\
\hline Total & 174 & 100 \\
\hline
\end{tabular}

\begin{tabular}{|c|c|c|c|}
\hline \multicolumn{2}{|c|}{ Males } & \multicolumn{2}{c|}{ Females } \\
\hline No. & $\mathbf{\%}$ & No & $\mathbf{\%}$ \\
\hline 76 & 43.67 & 98 & 56.32 \\
\hline
\end{tabular}

\section{TABLE NO. 1: DISTRIBUTION OF PATIENTS ACCORDING TO AGE}

\begin{tabular}{|c|c|c|}
\hline \multirow{2}{*}{ Factors } & \multicolumn{2}{|c|}{$\begin{array}{c}\text { Notal } \\
\text { N=174 }\end{array}$} \\
\cline { 2 - 3 } & No & \% \\
\hline Family history & 21 & 12.06 \\
\hline Hypertension & 71 & 40.80 \\
\hline Diabetes Mellitus & 73 & 41.95 \\
\hline Raised serum cholesterol levels & 41 & 23.56 \\
\hline Smoking & 45 & 25.86 \\
\hline Alcohol consumption & 34 & 19.54 \\
\hline Sun exposure & 86 & 49.42 \\
\hline
\end{tabular}

TABLE NO. 4: RELATIONS OF AMD WITH ASSOCIATED SYSTEMIC RISK FACTORS 
Diabetes (42.5\%) and Hypertension (41.8\%) were the most common risk factor associated with AMD. They were associated in $64.28 \%$ cases with exudative AMD.

Raised S. cholesterol levels and smoking were associated in $23.56 \%$ \& $25.86 \%$ cases respectively.

Alcohol consumption was associated with $17.5 \%$ cases of non exudative AMD and $42.85 \%$ cases of Exudative AMD.

21 patients (12.06\%) gave a po sitive family history for AMD.

Sun exposure was associated with $49.42 \%$ cases of AMD

\begin{tabular}{|c|c|c|}
\hline \multirow{2}{*}{ Factors } & \multicolumn{2}{|c|}{ Notal } \\
& \multicolumn{2}{|c|}{ N74 } \\
\cline { 2 - 3 } & No & $\mathbf{\%}$ \\
\hline Light Iris color & 19 & 10.91 \\
\hline Hypermetropia & 45 & 25.86 \\
\hline Pseudophakia & 47 & 27.01 \\
\hline Aphakia & 2 & 1.14 \\
\hline
\end{tabular}

TABLE NO. 5: RELATIONS OF AMD WITH ASSOCIATED OCULAR RISK FACTORS

Majority of the patients (45.39\%) aged $>70$ years. $51(29.3 \%)$ patients were in the $61-70$ yrs age group ,while $44(25.28 \%)$ patients belonged to 51-60 years age group.

Females were affected more (98) as compared to males (76) with overall male to female ratio of $0.75: 1$.

Hypertension $41.8 \%$ was the most common risk factor associated with AMD.

Raised S. cholesterol levels in $23.56 \%$ and smoking were associated with $25.86 \%$ cases.

Alcohol consumption was associated with $60.3 \%$ cases

In $12.06 \%$ patients a positive family history for AMD was seen.

Sun exposure was associated with $49.42 \%$ cases of AMD.

DISCUSSION: Age related macular degeneration (AMD) is the leading cause of central visual loss among individuals 65 years of age and older in the developed countries. This impairment adversely affects activities of daily living, rendering it more difficult to read, write, with those in the advanced stages often developing loss of central vision leading to legal blindness. The prevalence of this disease is increasing as the proposition of our elderly population rises, which underscores the growing impact of this problem on our society

The average age at onset of visual loss is about 75 years. In the present study majority of the patients $79(45.39 \%)$ were above the age of 70 years, with 51 (29.31\%) patients between 61-70 years and 44 cases (25.28\%) in the sixth decade. The Framingham eye study (1975) cited a prevalence of approximately 2\% in Americans aged 52-64 years, 11\% in those $65-74$ yrs and $28 \%$ in those 75 years or older. Though the prevalence of disease increased with age in both studies, the disparity could be due to the fact that the Framingham eye study (1975) was a population based study while ours was a hospital based study and included small number of patients (174).

In our present study females were affected more as compared to males with the overall male: female ratio being 0.75:1. Both non exudative and exudative AMD was more in females with M: 
F ratio being $0.73: 1 \& 0.5: 1$ respectively. This corroborated with the study conducted by the National Health and Nutrition Examination Survey (NHANES) III, 1995, which reported a lower prevalence of AMD among men regardless of race and age. The Blue Mountain Eye Study, 1995 also reported a consistent sex difference in prevalence of AMD, with women having higher rates.

Gass JD 1997 suggested an autosomal dominant inheritance with variable penetrance. Francois J. 1977 stated that nearly one fourth of parents, siblings and offspring's of patients who have AMD manifest the disease concurrently. In our study $21(12.06 \%)$ patients have a positive family history of AMD. A proper evaluation of hereditary factor could not be undertaken due to lack of proper medical record and largely illiterate population.

The Eye Disease Case Control Study Group, 1992 stated systemic arterial hypertension and cigarette smoking to be associated with increased risk of neovascular AMD. In this study 28.57\% cases of exudative AMD and 41.8\% patients of non-exudative AMD were hypertensive. In our study $25.26 \%$ cases gave history of smoking out of which $57.14 \%$ cases had exudative AMD while $23.12 \%$ cases had non-exudative AMD. This corresponded with the study conducted by Wilson GA, Field AP, Wilson $\mathrm{N}$ in 2001 in New Zealand in which positive history of smoking was present in 26.8\% patients of all AMD.

Raised serum cholesterol levels were seen in $14.28 \%$ cases of exudative AMD in our study while $24.37 \%$ cases of non exudative AMD had increased S. cholesterol levels. This corroborated with the findings of EDCLS (1996) which reported a statistically significant fourfold increased risk of exudative AMD with raised S. cholesterol levels. In our study $17.5 \%$ cases of non-exudative AMD and $42.85 \%$ cases of exudative AMD gave history of alcoholism.

In the EDCCS, a significant relationship between alcohol intake and exudative AMD was noted in univariate analyses. Hyman LG, Lilienfeld AM et al 1983 reported significant association between sunlight exposure and development of AMD. In our study $49.42 \%$ patients gave positive history of sun exposure.

CONCLUSION: Age related macular degeneration is a bilateral disease occurring in later decades of life. Improved health conditions and prolonged life span has increased the incidence of this disease. The age at presentation in most cases in above 70 yrs. Females are affected more often than males in both types of AMD. Our study confirms that AMD is associated with numerous risk factors, most of them are preventable. Risk factors were hypermetropia, diabetes, hypertension, increased serum cholesterol levels, smoking, lower intake of antioxidants, higher fat intake and prolonged sun exposure. A proper family history needs to be taken to comment on familial inheritance of AMD. Thus awareness about these risk factors, early diagnosis and timely intervention with treatment and reduce visual disability in the advanced age.

\section{REFERENCES:}

1. Age-Related Eye Disease Study Group: Age-Related Eye Disease Study (AREDS) Phase II Manual of Operations. Potomac MD, the Emmes Corporation, 1992.

2. Cruickshanks KJ, Klein R, Klein BEK: Sunlight and age-related macular degeneration: The Beaver Dam Eye Study. Arch Ophthamol 111:514-518, 1993. 
3. Eye Disease Case-Control Study Group: Antioxidant states in neovascular age-related macular degeneration. Arch Ophthalmol 111:104-109, 1993.

4. The Eye Disease Case-Control Study Group: Risk factors for neovascular age-related macular degeneration. Arch Ophthalmol 110:1701-1706, 1992.

5. Kahn HS, Leibowitz HM, Ganley JP, et al. The Framingham Eye Study: II. Association of ophthalmic pathology with single variables previously measured in the Framingham Heart Study. Am J Epidemiol. 1977; 106:33-41.

6. National Advisory Eye Council Vision Research: A National Plan, 1983-1987. United States Department of Health and Human Services; Bethesda, MD: 1984. Publication NIH 83-2471.

7. Klein R, Klein BEK, Linton KLP. Prevalence of age-related maculopathy. The Beaver Dam Eye Study. Ophthalmology. 1992; 99:933-43.

8. Bressler NM, Bressler SB. Preventative ophthalmology. Age-related macular degeneration [review] Ophthalmology. 1995; 102:1206-11.

9. Bressler NM, Bressler SB, West SK, et al: The grading and prevalence of macular degeneration in Chesapeake Bay waterman. Arch Ophthalmol 107:847-852. 1989.

10. Klein R, Klein Linton KLP: Prevalence of age-related maculopathy, The Beaver Dam Eye Study. Ophthalmology 99:933-943, 1992.

11. Vingerling JR, Diel emans I, Hofman A, et al: The Prevalence of age-related maculopathy in the Rotterdam Study. Ophthalmology 102:205-210, 1995.

12. West SK, Rosenthal FS, Bressler NM, et al: Exposure to sunlight and other risk factors for agerelated macular degeneration. Arch Ophthamol 107:875-879, 1989.

13. Goldberg J, Flowerdew G, Smith E, et al: Factors associated with AMD: Analysis of the first NHANES. Am J Epidemiol 128:700-710, 1988.

14. Klein R, Klein BEK, Franke T: The relationship of cardiovascular disease and its risk factors to age-related maculopathy. The Beaver Dam Eye Study. Ophthalmology 100:406-414, 1993.

15. Eye Disease Case-Control Study Group: Antioxidant states in neovascular age-related macular degeneration. Arch Ophthalmol 111:104-109, 1993.

16. Seddon JM, Ajani UA, Sperduto RD, et al: Dietary carotenoids, vitamins A, C, and E, and advanced age-related macular degeneration. JAMA 272:1413-1420, 1994.

17. Seddon JM, Willett WC Speizer FE, Hankinson SE, A prospective study of cigarette smoking and age-related macular degeneration in women. JAMA 276:1141-1146, 1996.

18. Leibowitz HM, Krueger DE, Maunder LR et al: The Framingham Eye Study Monograph. Surv Ophthalmol 24 (S): 335-610, 1960.

19. Mitchell P, Smith W, Attebo K, Wang JJ: Prevalence of age-related maculopathy in Australia: The Blue Mountains Eye Study. Ophthalmology 102:1450-1060, 1995.

20. National Center for Health Statistics: Plan and operation of the NHANES III, United State 1988-1994, Vital Health Stat 1(32), 1994.

21. Sandberg MA, Gaudio AR, Miller S, et al: Iris pigmentation and extent of disease in patients with neovascular age-related macular degeneration. Invest Ophthalmol Vis Sci 35:27342740, 1994.

22. Gibson JM, Shaw DE, Rosenthal AR: Senile cataract and senile macular degeneration: An investigation into possible risk factors. Trans Ophthalmol Soc UK 105:463-468, 1986. 
23. Smith W, Mitchell P, Leeder SR, Smoking and age-related maculopathy. The Blue Mountains Eye Study. Arch Ophthalmol 114:1518-1523, 1996.

24. Hyman LG, Lilienfeld AM, Ferris FL III, et al. Senile macular degeneration, a case control study. Am J Epidemiol 1983; 118: 213-27.

25. Jain IS, Prasad P, Gupta A, et al. Senile macular degeneration in India. Ind J Ophthalmol 1984; 32: 343-6.

26. Narendran V, Tulsiraj RD, Kim R, et al. The prevalence of age-related maculopathy in South India. Invest Ophthalmol Vis Sci (abstract) 2000; 41: s119.

27. Wilson GA, Field AP, Wilson N. Smoke gets in your eyes: smoking and visual impairment in New Zealand. NZ Med J 2001; 114: 471-

\section{AUTHORS: \\ 1. Kavita Kumar \\ 2. Pooja Bargujar \\ 3. V. Som \\ 4. S. Kubrey}

\section{PARTI CULARS OF CONTRIBUTORS:}

1. Associate Professor, Department of Ophthalmology, Regional Institute of Ophthalmology, Gandhi Medical College. Bhopal.

2. Senior Resident, Department of Ophthalmology, Regional Institute of Ophthalmology, Gandhi Medical College. Bhopal.

3. Assistant Professor, Department of Ophthalmology, Regional Institute of Ophthalmology, Gandhi Medical College. Bhopal.
4. Assistant Professor, Department of Ophthalmology, Regional Institute of Ophthalmology, Gandhi Medical College. Bhopal.

\section{NAME ADDRESS EMAIL ID OF THE CORRESPONDING AUTHOR:}

Dr. Kavita Kumar,

A-43, Shahpura, Bhopal - 462039.

Email - kavita.kumar43@ gmail.com

Date of Submission: 08/10/2013.

Date of Peer Review: 10/10/2013.

Date of Acceptance: 19/10/2013.

Date of Publishing: 30/10/2013 